\title{
Thermal Properties of Plasticized Poly (Lactic Acid) (PLA) Containing Nucleating Agent
}

\author{
Seyedmohammadkazem Fehri, Patrizia Cinelli, Maria-Beatrice Coltelli, Irene Anguillesi, and Andrea \\ Lazzeri
}

\begin{abstract}
The present research reports the investigation of the role of an oligomeric polyadipate plasticizer (206 3NL), and a nucleating agent aromatic sulfonate derivative (LAK301) on thermal behaviours of poly-lactic acid (PLA) evaluated through differential scanning calorimetry (DSC) measurements in order to investigate the separated effect due to the addition of plasticizer and nucleating agent on the thermal behavior of PLA respectively. Binary and ternary systems containing PLA/206 3NL/LAK301 have been developed. All samples have been prepared by melt-blending. The results of the present study show that LAK301 acts as a very efficient nucleating agent by increasing crystallinity percentage from $5.6 \%$ in pure PLA to $12 \%$ in PLA/LAK301 5\%wt/206 3NL, and that (206 3NL) is a compatible plasticizer for PLA as the glass temperature drops down from $59.4{ }^{\circ} \mathrm{C}$ in pure PLA to $38.9{ }^{\circ} \mathrm{C}$ in blends of PLA-NL $15 \mathrm{wt} \%$. Also the approach of investigating the compatibility in ternary system where the plasticizer and nucleating agent have a synergic effect on thermal properties as well on crystallinity and glass transition temperature of PLA were addressed. In fact in ternary blends of PLA/LAK301/206 3NL with 5 wt \% of LAK301 the glass transition temperature was reduced to $30.3{ }^{\circ} \mathrm{C}$ and PLA crystallinity increased to 39 wt\%.
\end{abstract}

Index Terms-Crystallinity, nucleating AGENT, POLY LACTIC ACID (PLA), thermal properties.

\section{INTRODUCTION}

Polylactic acid (PLA) as compostable, thermoplastic and aliphatic polyester which can be produced from annually renewable resources, is currently considered an alternative choice for synthetic plastic materials in the food packaging market due to its relatively low cost and good processability. This polymer is expected to reduce the impact on the environment due to the production and use of petrochemical polymers [1].

In recent years, investigation on the crystallization behavior of PLA attracts much attention because the degree of crystallinity $\left(X_{c}\right)$ determines most of the performance of PLA. Poly (lactic acid) has a slow-crystallization rate, affecting its processing and limiting its use in plastic or film

Manuscript received April 14, 2015; revised June 25, 2015. This work is part of the EC Project DIBBIOPACK Development of injection and extrusion blow molded biodegradable and multifunctional packages by nanotechnologies" GA: n 280676

S. Fehri, P. Cinelli, and A. Lazzeri are with the Department of Civil and Industrial Engineering, Pisa University, Largo Lucio Lazzarino 1, 56126, Pisa, Italy and INSTM, Via G. Giusti, 9, 50121 Firenze, Italy (e-mail: s.fehri@studenti.unipi.it, andrea.lazzeri@unipi.it).

I. Anguilles and B. Coltelli are with the Department of Civil and Industrial Engineering, Pisa University, Largo Lucio Lazzarino 1, 56126 , Pisa, Italy (e-mail: irene.anguillesi@unipi.it, mb.coltelli@ing.unipi.it). applications.

The main drawback in application of semi crystalline PLA based materials is due to PLA brittle behavior and the low thermal resistance, due to glass transition temperature $(\mathrm{Tg})$ of about $60^{\circ} \mathrm{C}$ [2].

In principle, PLA based materials that are able to maintain their mechanical properties at a temperature above $\mathrm{Tg}$ and below the melting temperature can be obtained by a crystallization process.

The most efficient way is improving the chain mobility of Poly (lactic acid) to form better crystalline structure.

Another way to improve the crystallization behavior is applying nucleating agent to decrease the nucleating activation energy and promote heterogeneous nucleation effect to achieve higher crystallinity inside Poly (lactic acid) or either by physical mixing with a second polymer component, immiscible with the PLA [3], [4].

Plasticizers such as poly (ethylene glycol) PEG, Oligomeric lactic acid, Citrate Ester and different nucleating agents such as calcium carbonate, Talc, Boron Nitride were proposed to improve thermal properties of PLA while PLA modifications are carried out more rarely [4]-[8].

According to author knowledge, few studies have been done to investigate the combined effect of both plasticizer and nucleating agent on crystallization rate of PLA.

Huneault [5] investigated the effect of heterogeneous nucleating agent by adding both talc and PEG in PLA matrix. The results showed that talc can be an effective nucleating agent and PEG was an efficient plasticizer inducing an increasing in crystallization even at fast cooling rates [6], [7]. B. Suksut et al. [8] also studied the effect of both plasticizer and nucleating agent on mechanical and thermal properties of PLA. Their results showed that the presence of nucleating agents (Cyclodextrin (CD)), Calcium carbonate $(\mathrm{CaCO} 3)$ and Talc in neat PLA increases the degree of crystallinity. Muller J. et al. [9], studied isothermal cold crystallization of PLA/PBAT (poly butylene adipate-co-terephthalate) blends with and without the addition of ATBC (acetyl tributyl citrate) and the results showed a synergic effect on the increase in the overall crystallization rate of the PLA when both ATBC and PBAT were present in the blends.

Recently, GLYPLAST ${ }^{\circledR} 206$ 3NL was introduced as a low viscosity saturated polyester and is suggested to be an excellent plasticizer for PLA. According to the supplier's data sheet, GLYPLAST ${ }^{\circledR 206} 3 \mathrm{NL}$ is an alternative for monomeric plasticizer, limiting plasticizer losses due to volatility, migration or extraction and it is, in particular, resistant to extraction.

As a nucleating agent with molecular formula 
(C10H9KO7S) and platelet shape, LAK301 can be used as a nucleating agent in the PLA matrix system. In particular in this work binary PLA/LAK301 compounds and ternary PLA/LAK301/206 3NL compounds were prepared with the aim of LAK301 as nucleating agent and $2063 \mathrm{NL}$ as novel plasticizer to improve thermal properties moulding also tensile properties of PLA. The crystallization behavior of the plasticized PLA (with and without nucleating agent) was also studied by differential scanning calorimetry (DSC).

\section{EXPERIMENTAL PROCEDURE}

\section{A. Material}

Poly (lactic acid) 2003D was provided by Nature Works LLC., USA (average molecular weight 200,000 g/mol, melting point temperature $210{ }^{\circ} \mathrm{C}$, glass temperature $T_{g}=55$ $58{ }^{\circ} \mathrm{C}$ ); LAK301 (Dimethyl 5-sulfoisophthalate, potassium salt) having a density of $1.00 \mathrm{~g} / \mathrm{cm}^{3}$ and a platelet shape (Fig. 1), was purchased from Takemoto oil and fat Co. Ltd.

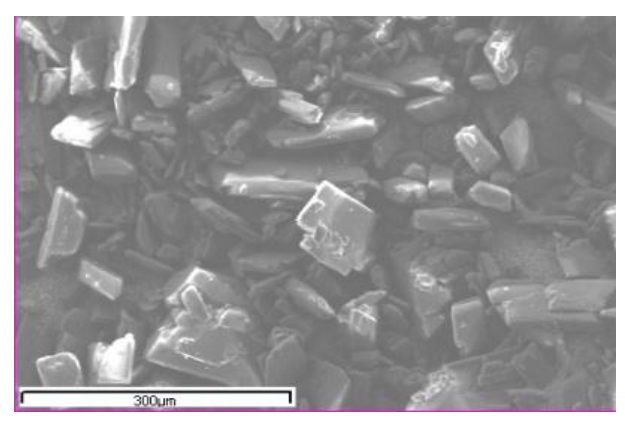

Fig. 1. SEM micrograph of the LAK301 (M 300).

GLYPLAST ${ }^{\circledR} 206$ 3NL (polyester of adipic acid with 1,3butanediol, 1,2-propanediol and 2-ethyl-1-hexanol) a saturated polyester with the density of $1,07\left(\mathrm{~g} / \mathrm{cm}^{3}\right.$ at $\left.25^{\circ} \mathrm{C}\right)$ andwas kindly provided by Condensia Quimica S.A (Spain).

TABLE I: COMPOSITION OF PLA BASED SAMPLES

\begin{tabular}{ccc}
\hline \hline PLA & LAK301 & 206 3NL \\
\hline 100 & 0 & 0 \\
99 & 1 & 0 \\
97 & 3 & 0 \\
95 & 5 & 0 \\
85 & 0 & 15 \\
84.2 & 1 & 14.9 \\
82.5 & 3 & 14.6 \\
80.8 & 5 & 14.3 \\
\hline \hline
\end{tabular}

\section{B. Preparation of Blends and Composite Materials}

PLA and LAK301 were dried at $65{ }^{\circ} \mathrm{C}$ under vacuum (1 $\mathrm{mm} \mathrm{Hg}$ ), two days before the use. Binary and ternary systems, reported in Table I were prepared by processing in a COMAC "HIGH-VOLUME" EXTRUDER (D/d ratio $\approx$ 1.65, Screw number of lobes: 2, Numbers of Heating zone: 11, Output: $20 \mathrm{~kg} / \mathrm{h}$, mod. COMAC EBC - Italy) with rotating speed of $220 \mathrm{rpm}$. The blends were extruded through a multi holes die $(3 \mathrm{~mm})$, and then converted to granules, dried at $65^{\circ} \mathrm{C}$ overnight before further processing on ALLROUNDER $920 \mathrm{~S}$ injection molding machine. Specimens of the ASTM D638 V dog-bone were produced, and samples from them used for thermal characterizations. In the injection condition the set temperature from feed zone to nozzle $190 / 180 / 160^{\circ} \mathrm{C}-155 / 150 / 130^{\circ} \mathrm{C}$ were used as injection conditions. Molding temperature and cooling time were $120^{\circ} \mathrm{C}$ and $240 \mathrm{~s}$, respectively.

The materials produced were immediately packed in plastic bags for vacuum sealing to prevent water absorption.

\section{CHARACTERIZATION}

Thermal analysis was performed in nitrogen atmosphere with a TA differential scanning calorimeter (mod. Q200, USA) on $7 \pm 0.3 \mathrm{mg}$ of sample. The samples were heated from -100 to $200^{\circ} \mathrm{C}$ at a rate of $10{ }^{\circ} \mathrm{C} / \mathrm{min}$ (first heating) and held for 2 minutes at $200{ }^{\circ} \mathrm{C}$ in order to erase the thermal history. Subsequently, the samples were cooled down to $100^{\circ} \mathrm{C}$ at a rate of $20^{\circ} \mathrm{C} / \mathrm{min}$ and heated again to $200{ }^{\circ} \mathrm{C}$ through a constant heating rate of $10{ }^{\circ} \mathrm{C} / \mathrm{min} . T_{g}$ was measured at the inflection point in heat flow versus temperature trend on the first and second heating scans between 25 and $200{ }^{\circ} \mathrm{C}$.

The degree of crystallinity $X_{c}(\%)$ of PLA was calculated using the following (1):

$$
X_{c}(\%)=\frac{\Delta H_{m}}{\Delta H_{m}^{\circ}}
$$

where $\Delta H_{m}$ is the melting enthalpy $(\mathrm{J} / \mathrm{g})$ of the sample, $\Delta H_{m}^{\circ}$ is the melting enthalpy of the $100 \%$ crystalline PLA $(93.7$ $\mathrm{J} / \mathrm{g}$ ) [9].

\section{RESULTS AND DISCUSSIONS}

DSC data are reported in Table II referred to second heating, they include glass transition temperature $\left(T_{g}\right)$, crystallization peak temperature $\left(T_{c}\right)$, melting temperature $\left(T_{m}\right)$, melting enthalpy $\left(\Delta H_{m}\right)$ and crystallinity percentage $(\% \mathrm{C})$. Non-detected values are due to very slow crystallization rate versus the DSC scan rate, $10^{\circ} \mathrm{C} / \mathrm{min}$.

\begin{tabular}{ccccccc} 
TABLE II: THERMAL CHARACTERIZATION OF PLA AND LAK301/206 3NL \\
COMPOSITES (SECOND HEATING) \\
\cline { 2 - 7 } & $\begin{array}{c}\Delta H_{m} \\
(\mathrm{~J} / \mathrm{g})\end{array}$ & $\begin{array}{c}\text { Cryst } \\
(\%)\end{array}$ & $\begin{array}{c}T_{c} \\
\left({ }^{\circ} \mathrm{C}\right)\end{array}$ & $\begin{array}{c}T_{g} \\
\left({ }^{\circ} \mathrm{C}\right)\end{array}$ & $\begin{array}{c}T_{m 1} \\
\left({ }^{\circ} \mathrm{C}\right)\end{array}$ & $\begin{array}{c}T_{m 2} \\
\left({ }^{\circ} \mathrm{C}\right)\end{array}$ \\
\cline { 2 - 7 } PLA & 5.22 & 5.6 & 108.8 & 59.4 & 148 & 154 \\
PLA-1\%LAK & 10.1 & 10.8 & 104.6 & 56.7 & 145 & 154 \\
PLA-3\%LAK & 8.29 & 8.8 & 106.5 & 59.9 & 148 & 153 \\
PLA-5\%LAK & 11.2 & 12 & 104.5 & 60.0 & 149 & 153 \\
PLA-NL & 8.54 & 9.12 & 85.04 & 38.9 & 138 & 152 \\
PLA-NL-1\%LAK & 36.1 & 38.6 & $\mathrm{nd}$ & 40.1 & 149 & 153 \\
PLA-NL-3\%LAK & 34.4 & 36.8 & $\mathrm{nd}$ & 34.1 & 146 & 152 \\
PLA-NL-5\%LAK & 36.5 & 39.0 & $\mathrm{nd}$ & 30.2 & 147 & 153 \\
\hline \hline
\end{tabular}


Results from Table II indicate that the plasticizer is partially miscible in the PLA matrix. In fact all plasticized samples show decreased value in $T_{g}$. As an example, the value of $T_{g}$ in pure PLA shifted from $59.4{ }^{\circ} \mathrm{C}$ to $30.2{ }^{\circ} \mathrm{C}$ in PLA/206 3NL with 5 wt\% LAK301 as shown in Fig. 2.

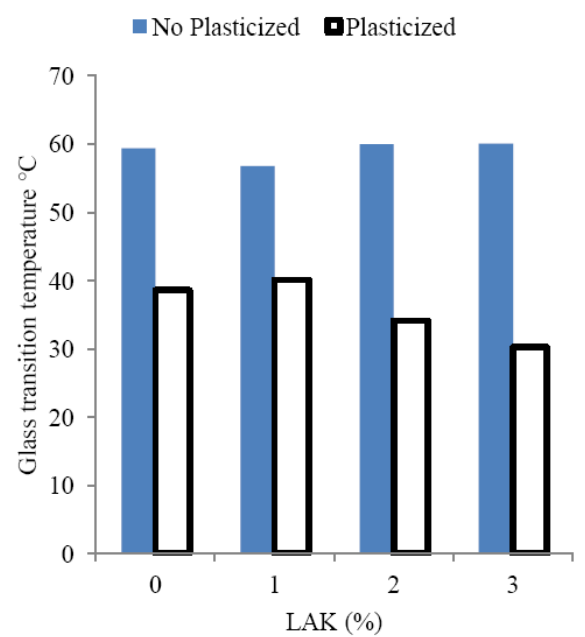

Fig. 2. Dependence of glass transition temperature on LAK301 content.

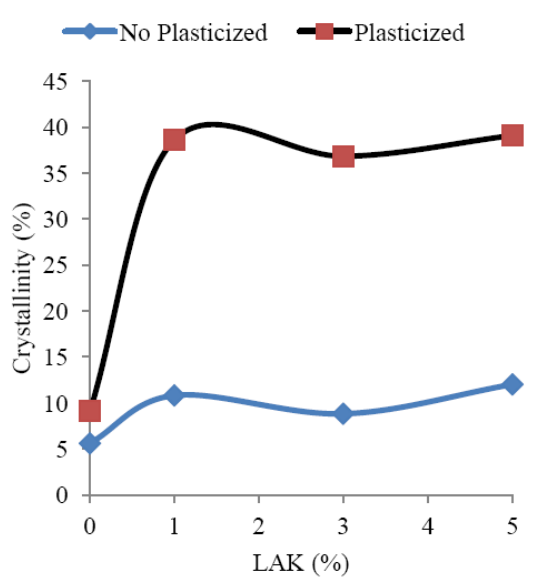

Fig. 3. Dependence of crystallinity on LAK301 content.

The decreased $T_{g}$ indicates that 206 3NL plays the role of a plasticizer on the PLA by facilitating the segmental mobility of the PLA chains.

There are not significant changes in glass transition temperature in binary blends of PLA/LAK301 with increasing amount of LAK301, thus LAK301 has not a relevant action as plasticizer or filler.

As reported previously, PLA crystallization can be increased by adding nucleating agent, alone or in presence of plasticizers. According to the values reported in Table II and Fig. 3, the addition of a nucleating agent such as LAK301 increased the crystallinity percentage. It also induced a more significant effect in composition with both plasticizer and LAK301, thus the maximum value for crystallinity (39.0\%) was observed in PLA/206 3NL/LAK301 5wt\%.

Moreover, the value of the melting enthalpy $\left(\Delta H_{m}\right)$ in ternary systems increased. In fact the melting enthalpy in pure PLA increased from $5.22(\mathrm{~J} / \mathrm{g})$ to $36.55(\mathrm{~J} / \mathrm{g})$ in ternary PLA/206 3NL/LAK301 5\%wt system in corresponding with degree of crystallinity.

It should be pointed out that reduction in $T_{g}$ enabled crystallization to start at lower temperature upon heating.
The DSC results from first round (not presented here) confirmed this matter. In good accordance also the coldcrystallization of PLA in the second heating was at $108{ }^{\circ} \mathrm{C}$ in pure and $85^{\circ} \mathrm{C}$ in PLA/206 3NL. Besides, the presence of the nucleating agent which is already formed during the cooling process caused heterogeneous nucleation to overcome the free energy barrier; and thus inducing higher and faster nucleation [10], [11]. Therefore, all of these components promote crystallinity while they provide a lower cold crystallization temperature. The cold crystallization temperature in ternary system could not be detected probably due to the high degree of crystallinity [12], [13]. Nevertheless, in binary systems the effect of nucleating agent on cold crystallization was not prominent.

The DSC curves in second heating round of pure PLA and the PLA/206 3NL/LAK301 composites are shown in Fig. 4. Upon the second scanning, the melting peaks of all the compositions show two endothermic peaks attributed to the two types of crystalline phases in PLA compositions ( $\alpha$, and $\alpha^{\prime}$ ) [9], [11] which became more pronounced when the plasticizer is added.

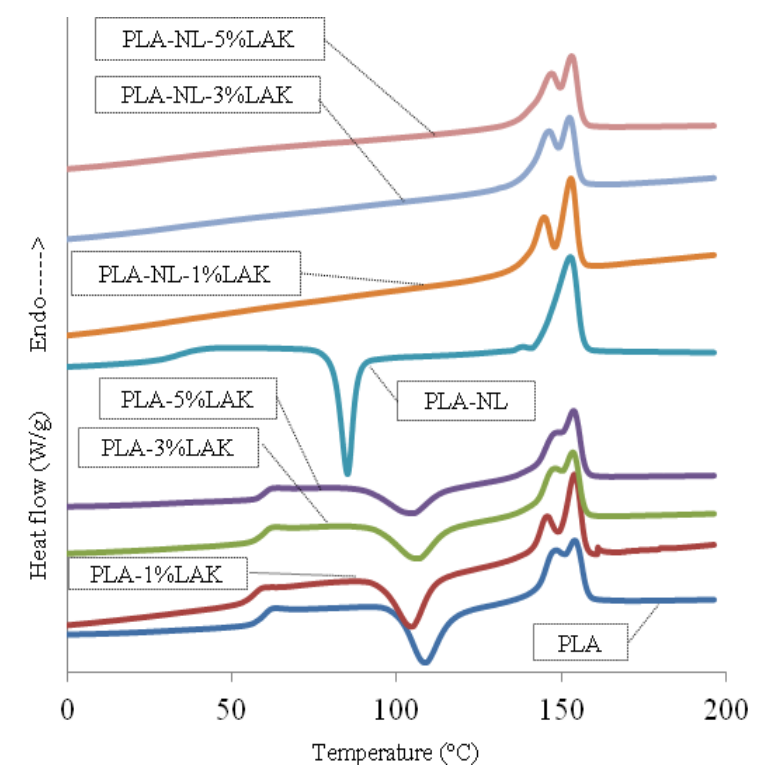

Fig. 4. DSC analyses of samples in heating.

The first peak corresponds to the melting of thinner crystals and the second peak is attributed to the melting of more stable crystals.

\section{CONCLUSION}

The authors within the current research, produced PLA with different contents of nucleating agent (LAK301) and plasticizer (206 3NL), and further investigated the thermal behavior of PLA in the presence of mentioned additives. The results of the study revealed that LAK301 acts as nucleating agent in PLA matrix and leads to increased crystallinity. Moreover, plasticizer (206 3NL) significantly favours the crystallization of PLA while in blend with LAK301 finds synergic effect to increase crystallinity and decreases glass transition temperature in PLA matrix.

Therefore this study can be useful for moulding processability and thermo-mechanical properties in several application, especially in injection moulding. 


\section{ACKNOWLEDGMENT}

This study is a part of EC Project DIBBIOPACK "Development of injection and extrusion blow molded biodegradable and multifunctional packages by nanotechnologies: improvement of structural and barrier properties, smart features, and sustainability" GA: $\mathrm{n}^{\circ}$ 280676, "NMP2011.LARGE.5 Large-scale integrating collaborative projects.

\section{REFERENCES}

[1] H. Liu and J. Zhang, "Research progress in toughening modification of poly(lactic acid)," J. Polym Sci Part B: Polym Phys, vol. 49, pp 1051-1083, 2011.

[2] L. T. Lim, R. Auras, and M. Rubino, "Processing technologies for poly(lactic acid)," Prog Polym Sci, vol. 33, pp. 820-852, 2008.

[3] J. M. Raquez, Y. Habibi, M. Murariu, and P. Dubois, "Polylactide (PLA)-based nanocomposites," Prog Polym Sci., vol. 38, pp. 15041542, 2013.

[4] J. M. Raquez, Y. Habibi, M. Murariu, and P. Dubois, "Polylactide (PLA)-based nanocomposites," Prog Polym Sci. vol. 38, pp. 15041542, 2013.

[5] S. Saeidlou, M. A. Huneault, H. Li, and C. B. Park, "Poly(lactic acid) crystallization," Prog Polym Sci, vol. 37, pp. 1657-1677, 2012.

[6] D. Battegazzore, S. Bocchini, and A. Frache, "Crystallization kinetics of poly(lactic acid)-talc composites," eXPRESS Polym Lett, vol. 5 , no. 10, pp. 849-858, 2011.

[7] S. Xuetao, Z. Guangcheng, P. Thanh Vu, and L. Andrea, "Synergistic effects of nucleating agents and plasticizers on the crystallization behavior of poly(lactic acid)," Molecules, vol. 20, no. 1, pp.1579$1593,2015$.

[8] B. Suksut and C. Deeprasertkul, "Effect of nucleating agents on physical properties of poly(lactic acid) and its blend with natural rubber," J Polym Environ., vol. 19, pp. 288-296, 2011.

[9] E. Quero, A. J. Müller, F. Signori, M. B. Coltelli, and S. Bronco, "Isothermal Cold-Crystallization of PLA/PBAT blends with and without the addition of Acetyl Tributyl Citrate," Macromolecular Journal, vol. 213, pp. 36-48, 2012.

[10] J. F. Turner, A. Riga, A. O'Connor, J. Zhang, and J. Collis, "Characterization of drawn and undrawn poly-L-lactide films by differential scanning calorimetry," Journal of Thermal Analysis and Calorimetry. vol.75, pp. 257-268, 2004.

[11] M. Cocca, M. L. Di Lorenzo, M. Malinconico, and V. Frezza, "Influence of crystal polymorphism on mechanical and barrier properties of poly(L-lactic acid)," Eur. Polym. J, vol. 47, pp. 1073-1080, 2011.

[12] M. A. Rahman, D. D. Santis, and G. Spagnoli et al., "Biocomposites based on lignin and plasticized Poly(lactic acid)," Journal of Applied Polymer Science, pp. 129, 202-214, 2012.

[13] K. S. Kang, S. I. Lee, T. J. Lee, R. Narayan, and B. Y. Shin, "Effect of biobased and biodegradable nucleating agent on the isothermal crystallization of poly(lactic acid)," J. Chem. Eng, vol. 25, no. 3. pp. 599-608, 2008.

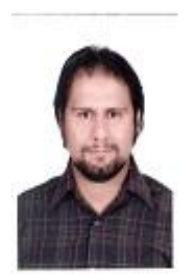

Seyedmohammadkazem Fehri is PhD student at the Department of Civil and Industrial Engineering, University of Pisa-Italy. He has master degree in materials science and engineering and works as researcher in DIBBIOPACK EC Project. His research activity is mainly focused on preparation and characterization of blends based on poly lactic acid and nano fillers to attain an improvement of the structural mechanical and gas barrier properties.

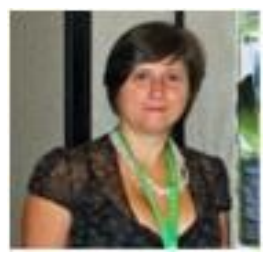

Patrizia Cinelli is a professor of applied chemistry and materials technology at Master Degree Students of Architecture Engineering, Pisa University. She has a $\mathrm{PhD}$ in chemistry at Pisa University, partly performed at the United States Department of Agriculture (USDA), Peoria, IL, USA. She has more than 20 years' experience in materials science and polymer technologies. She is the co-author of over 40 papers in peer reviewed journal, 8 book chapters, and 8 patents on innovative materials. Her research activity is mainly focused on biodegradable polymers processing and characterization, evaluation of compostability and sustainability by LCA analysis.

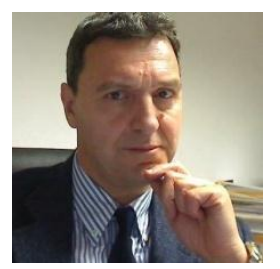

Andrea Lazzeri graduated in chemical engineering at University of Pisa in 1982. In 1991 he completed his $\mathrm{PhD}$ at Cranfield University. From 2009 he is a full professor of materials science and engineering. His research interests include toughening of polymers, interphase adhesion, plasticity, fatigue, fracture mechanics, processing of polymers and composites and have brought to the publication of over100 scientific papers. Prof. Lazzeri has coordinated the EC FP7, KBBE project FORBIOPLAST, and is coordinating the EC FP7, NMP project HELM. He leads the Research Group of the University of Pisa as a partner in seven running EC projects.

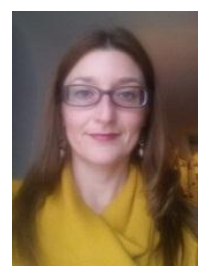

Maria-Beatrice Coltelli is a researcher in materials science at the University of Pisa. She graduated in chemistry and the $\mathrm{PhD}$ in chemical science (partly performed at Katholieke Universiteit Leuven, Belgium). Her researches were focused on polymer science, in particular polymer blends and nano-composites. She is the author of more than 35 international publications and patents. She followed the scientific activity of several European, National and Regional projects on biobased or recycled polymers, materials science and nano-technology. She currently supports the didactical activity of materials science courses for chemical engineers and construction engineers and is a professor of a chemistry course for naval engineers.

Irene Anguillesi is a chemist and technician skilled in materials characterization working in the Department of Chemical Engineering, Industrial Chemistry and Materials Science at University of Pisa from 1988. She is the author of 12 international papers. 